\title{
Revisão da bibliografia sobre bancadas temáticas e frentes parlamentares no Brasil (2011-2021)
}

\section{Introdução}

Nos últimos anos, qualquer pessoa que tenha acompanhado a política brasileira, seja pela TV, internet ou jornais, em algum momento se deparou com termos como "bancadas temáticas", "bancada evangélica", "bancada ruralista" e "bancada da bala". O argumento corrente é que esses grupos - formados por deputados federais e senadores membros de diferentes partidos - são responsáveis por uma importante atuação dentro do Congresso Nacional, e, portanto, devem ser acompanhados de perto. Como não poderia deixar de ser, o surgimento e o comportamento das bancadas temáticas e frentes parlamentares despertaram também o interesse acadêmico, em especial de pesquisadores das ciências humanas, que almejaram responder a algumas questões: como o seu desempenho pode ser observado? Em que bases está apoiada a atuação desses parlamentares? Essas indagações motivaram uma série de trabalhos produzidos nos últimos 30 anos, mas o assunto galgou especial saliência durante a última década. O objetivo deste artigo é realizar um balanço dessa bibliografia, analisando seus consensos, dissensos e lacunas.

Para compreender o interesse pelas bancadas e frentes parlamentares, é preciso acessar o que poderiam representar em termos de mudança na ordenação do arranjo político brasileiro. Não é recente o diagnóstico de que no Brasil, a partir

\footnotetext{
' Juliana Carvalho é mestre e graduada em Ciências Sociais pela Universidade Federal de São Paulo (UNIFESP). E-mail: carvalho.juliana02@unifesp.br. Pesquisadora Assistente do Centro de Estudos de Cultura Contemporânea (CEDEC), atua na área de Ciência Política Brasileira e Política Comparada, com ênfase em instituições políticas.

Publicado em: janeiro de 2022 | pp. 1-16
} 
de 1988, está em voga o que ficou conhecido como presidencialismo de coalizão, conceito clássico cunhado por Abranches (1988). Tendo em vista a multiplicidade de partidos representados no Congresso sem que nenhum obtenha maioria confortável, torna-se necessário que o Chefe do Executivo busque apoio para a agenda presidencial junto a um certo número de agremiações, compondo assim a sua coalizão. No plano legislativo, o argumento desenvolvido por Figueiredo e Limongi (2001) a partir de pesquisa empírica com foco em votações nominais demonstrou que, mediante os poderes assegurados aos líderes pelo Regimento Interno da Câmara, estes controlam o que será votado e como, além de sua orientação ser um ótimo preditor do voto dos parlamentares.

O diagnóstico e o desenvolvimento teórico acima citados têm permanecido estáveis na Ciência Política brasileira há pelo menos duas décadas e a ausência de mudanças nas regras do jogo parecem reafirmar esses argumentos. Entretanto, desde meados da Assembleia Nacional Constituinte, atores coletivos que não os partidos políticos têm sido apontados como possíveis outros organizadores da atividade parlamentar: as bancadas temáticas e frentes parlamentares. Grupos suprapartidários, com interesses tematicamente demarcados, estariam se organizando para influenciar os resultados no Legislativo. Apesar das primeiras análises datarem de cerca de trinta anos atrás, foi principalmente nos últimos dez anos que as bancadas e frentes se consolidaram como agenda de pesquisa. O interesse crescente - representado pelo número de produções científicas mais recentes - foi estimulado, entre outras coisas, pelo número cada vez maior destes grupos na política brasileira, pelas frequentes referências a eles feitas pela mídia e pelos próprios parlamentares, além dos possíveis desafios ao já consolidado padrão de organização no Legislativo brasileiro.

O presente artigo tem como objetivo elaborar uma revisão da literatura sobre as bancadas temáticas e frentes parlamentares no Poder Legislativo brasileiro e, para tal empreitada, seguido desta introdução, apresento um breve histórico das bancadas e frentes, de maneira a justificar o interesse pelo assunto. A seção posterior descreve os procedimentos pelos quais se constituiu o corpus da análise. Os resultados são relatados na seção seguinte, na qual são contabilizados os trabalhos disponíveis e suas características discutidas em relação aos seus avanços e limitações. As considerações finais buscam fazer uma avaliação crítica da bibliografia apresentada, além de sugestões para uma agenda futura sobre o tema.

\section{Bancadas temáticas, frentes parlamentares e a política brasileira}

O argumento sobre o crescimento das bancadas e frentes parlamentares como responsável pelo interesse acadêmico no tema e pelos trabalhos já publicados é recorrente neste artigo e os dados apresentados a seguir são ilustrativos dessa tendência. Entretanto, uma pequena distinção entre bancadas temáticas e frentes parlamentares se faz necessária. Essencialmente, bancadas temáticas são agrupamentos suprapartidários de parlamentares que se organizam em torno de interesses temáticos comuns. As frentes parlamentares, desde o Ato da Mesa $n^{\circ} 69$ de 10 de novembro de 2005, são grupos institucionalmente reconhecidos a partir de solicitação de registro junto à Câmara. A requisição deve ser feita mediante uma lista signatária de pelo menos $1 / 3$ dos membros do Legislativo o que representa 198 parlamentares entre deputados e senadores - e a solicitação é aceita a partir da verificação dessas assinaturas. $O$ registro precisa ser renovado a cada início de legislatura e não dá muitas prerrogativas aos grupos, 
uma vez que estes não podem contratar pessoal nem fornecer passagens aéreas, além das solicitações da utilização de espaços físicos para reuniões ficarem sujeitas à decisão da Mesa Diretora. Autores como Pierucci (1989), Frade (1996) e Bruno (2017) remontam a existência das bancadas evangélica e ruralista já em meados da Assembleia Nacional Constituinte, como forma de influenciar os resultados da futura Constituição de 1988. Contudo, o fenômeno parece ter se consolidado realmente a partir dos anos 2000. Devido ao seu caráter informal ${ }^{1}$, o número de bancadas temáticas é incerto, mas tendo como base os registros da Câmara dos Deputados, é possível estimar o número de frentes parlamentares de cada legislatura mediante o número de grupos aprovados por ano.

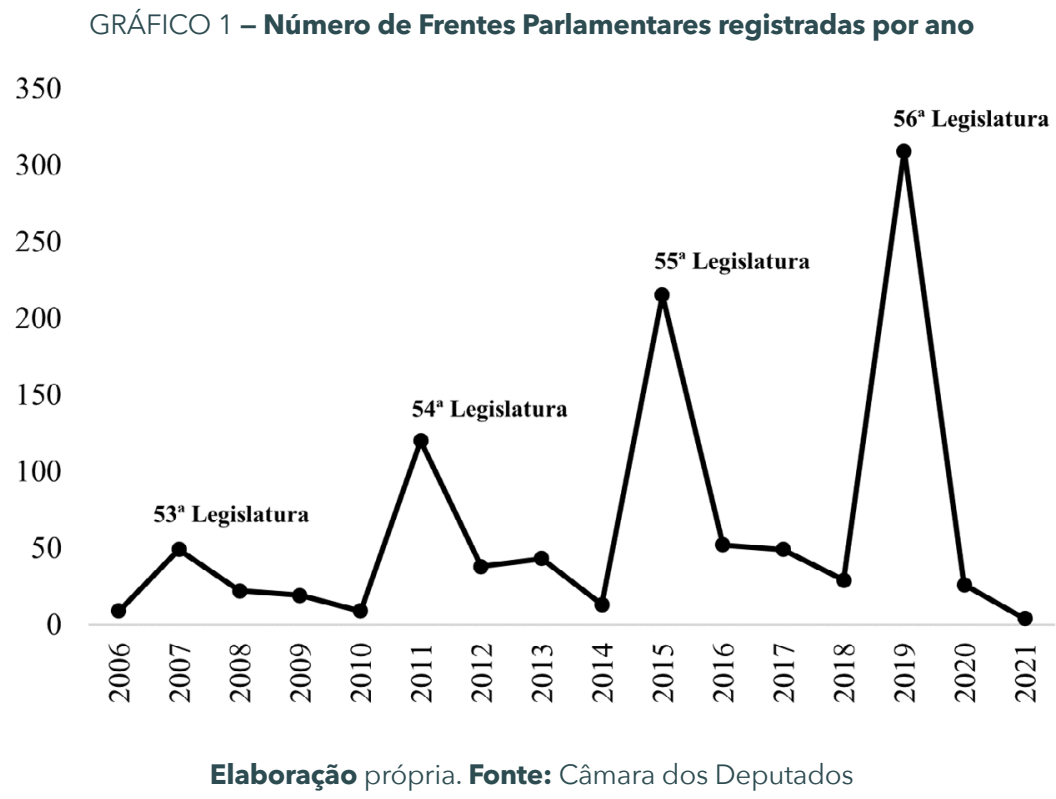

A partir do gráfico acima é possível notar uma tendência de crescimento das frentes registradas ao longo dos anos, e o número alto de requisições a cada início de legislatura é justificado em virtude da necessidade de renovação do registro. Além disso, há também as frentes nunca registradas que entram com suas solicitações no início das legislaturas. Diversos são os argumentos para este crescimento: representação de interesses não assimilados pelos partidos, demandas da sociedade civil, e, nos últimos anos, a suposição de que a presença nas frentes traria algum retorno eleitoral aos parlamentares ou que esses poderiam se beneficiar em negociações diretas com o Executivo.

\section{Fontes de pesquisa, seleção dos trabalhos e procedimentos metodológicos}

Para realizar a revisão bibliográfica aqui proposta, foram selecionados todos os artigos publicados em periódicos, dissertações de mestrado, teses de doutorado,

\footnotetext{
1 Em alguns casos, há autores que diferenciam fenômenos de um mesmo "tipo": a Frente Parlamentar da Agropecuária (FPA), por exemplo, seria diferente da bancada ruralista. A diferença estaria fundamentada na discrepância entre a lista signatária da FPA e a atuação efetiva dos parlamentares (Cascione e Araújo, 2019).
} 
livros, capítulos de livros e monografias produzidos nos últimos dez anos (20112021) que analisaram de maneira direta as bancadas temáticas e frentes parlamentares. Isso significa que, ainda que exista uma gama de outros trabalhos que citam as bancadas e frentes de maneira lateral, como por exemplo para discutir a inserção dos evangélicos na política ou a importância dos empresários rurais na tomada de decisões na Câmara dos Deputados e no Senado, compõem o corpus dessa análise somente os textos destinados ao estudo das bancadas e frentes propriamente ditas. Não foram incluídos na análise trabalhos publicados em anais de eventos, entrevistas e notícias de jornal, de maneira a considerar somente trabalhos que passaram por avaliação de pares. Ademais, foram considerados apenas textos que abordam a questão da perspectiva do Legislativo nacional, uma vez que a presença das bancadas temáticas e frentes parlamentares nas Câmaras municipais ainda é pouco expressiva como fenômeno e também em termos da produção científica ${ }^{2}$. Por fim, somente os trabalhos publicados sobre as bancadas e frentes no contexto do sistema político brasileiro foram incorporados. A principal razão para esta decisão diz respeito à ausência de trabalhos que abordem essas organizações parlamentares suprapartidárias em contexto internacional. Há no Brasil uma vasta literatura sobre lobby, organizações empresariais e grupos de interesse, mas é notável a pouca influência da literatura específica sobre os grupos conhecidos como legislative members organizations (LMOs) e que seriam o fenômeno mais próximo do que aqui conhecemos como frentes parlamentares. Uma breve leitura das citações dos textos examinados demonstra que trabalhos como o de Ringe et. al (2013), que versa sobra a existência e funcionamento das LMOs em mais de quinze países, não foram considerados nas análises já desenvolvidas.

A pesquisa pelos trabalhos se deu a partir da consulta dos termos "bancada(s) temática(s) ", "frente(s) parlamentar(es) ", "bancadas suprapartidárias" e "bancada(s) parlamentar(es) " nas plataformas Web Of Science e Google Scholar. Baseado nos critérios mencionados no parágrafo anterior, foi construído um banco de dados com as seguintes informações: 1) ano de publicação; 2) nome do(s) autor(es); 3) tipo de produção: artigo, capítulo de livro, dissertação, livro, monografia ou tese; 4) revista ou periódico da publicação, no caso de artigos; 5) palavras-chave, quando disponíveis; 6) tema; 7) número de citações do trabalho, quando disponível; 8) instituição, no caso de dissertações, monografias ou teses; 9) departamento, também nos casos de dissertações, monografias ou teses; 10) enfoque do trabalho: a) estudo de caso de um ou mais grupos específicos - como a bancada evangélica e/ou bancada da bala - buscando compreender seus mecanismos de atuação; b) observação de questões específicas de interesse de uma ou mais bancadas - como a união estável de pessoas do mesmo sexo ou a educação sexual nas escolas - com foco em seu comportamento nessa questão em especial; c) análise das bancadas e frentes de maneira geral, com o objetivo de construir esquemas metodológicos e teorias mais abrangentes sobre esses grupos.

A coleta dessas informações resultou em um corpus de 111 trabalhos defendidos e/ou publicados nos últimos 10 anos e outros 9 publicados antes disso. A seção a seguir detalha as características da produção científica sobre o tema das bancadas temáticas e frentes parlamentares com base nesses textos.

2 Foram localizados apenas dois trabalhos que abordem o tema das bancadas e frentes sob a perspectiva da política municipal. 


\section{O status da bibliografia sobre bancadas temáticas e frentes parlamentares}

Como apontado anteriormente, o interesse pelas bancadas temáticas e frentes parlamentares tem crescido desde que a sua presença foi notada no Poder Legislativo, em meados dos anos 1990. Contudo, um aumento ainda mais significativo deste interesse pode ser observado nos últimos dez anos, motivado, entre outras coisas, pela expressividade dos grupos junto à mídia e ao próprio parlamento. Isso se reflete nas pesquisas acadêmicas realizadas e este efeito pode ser verificado no gráfico de dispersão a seguir.

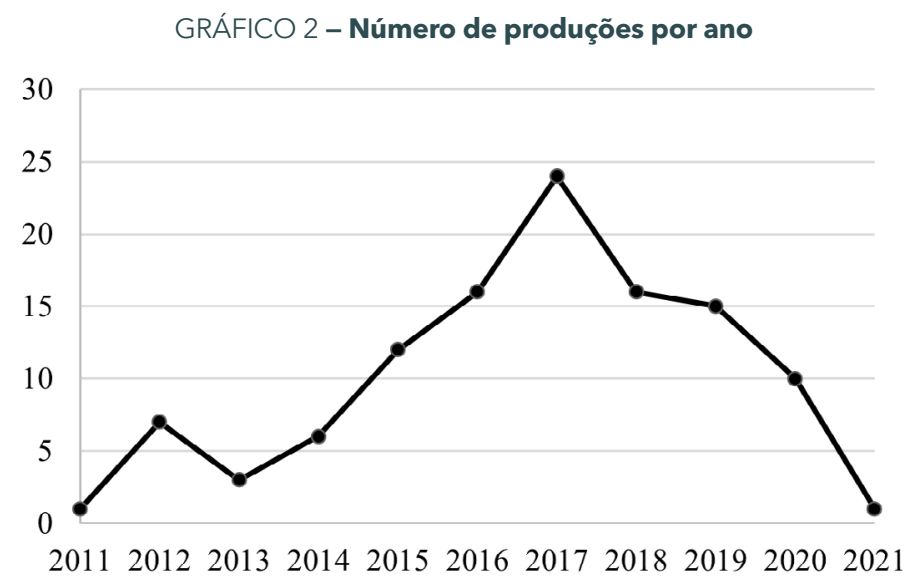

Elaboração própria. Fonte: Banco de dados da pesquisa.

O número total de trabalhos por ano demonstra que o auge das produções sobre as bancadas temáticas e frentes parlamentares ocorreu no ano de 2017, seguido de queda nos anos subsequentes. A queda representa uma redução de 8 trabalhos de 2017 para 2018, 1 trabalho de 2018 para 2019 e 5 trabalhos de 2019 para 2021. A comparação entre os anos de 2020 e 2021 fica prejudicada pois o ano de 2021 ainda está em andamento. De todo modo, fica claro que o número de textos produzidos sobre as bancadas e frentes tem diminuído e é necessário observar as tendências dos próximos anos para verificar se haverá alguma estabilização no número de produções por ano ou se o declínio se manterá, além das possíveis explicações para essa queda.

Além da produção por ano, o número de trabalhos por tipo dá ainda mais pistas sobre a maneira pela qual as bancadas temáticas e frentes parlamentares têm sido estudadas.

TABELA 1- Número e porcentagem de trabalhos por tipo

\begin{tabular}{lcc}
\hline TIPO DE TRABALHO & QUANTIDADE & $\%$ \\
\hline Artigo & 39 & $35 \%$ \\
Monografia & 33 & $30 \%$ \\
Dissertação & 25 & $23 \%$ \\
Tese & 7 & $6 \%$ \\
Capítulo de Livro & 5 & $4 \%$ \\
Livro & 2 & $2 \%$ \\
\hline Total & 111 & $100 \%$ \\
\hline
\end{tabular}

Elaboração própria. Fonte: Banco de dados da pesquisa. 
A partir do gráfico acima, pode-se observar que os artigos, monografias e dissertações compõem juntos $85 \%$ da produção sobre bancadas temáticas e frentes parlamentares no Brasil, enquanto os capítulos de livros e livros representam apenas $6 \%$ do total ${ }^{3}$. Tendo em vista a importância significativa de dissertações e monografias para a produção recente sobre o tema, identificar as universidades e departamentos de origem destes trabalhos auxilia também na análise dos lugares nos quais o conhecimento está sendo desenvolvido.

QUADRO 1 - Produção por universidades e departamentos

\begin{tabular}{|c|c|c|c|}
\hline UNIVERSIDADE & DEPARTAMENTO & TIPO & QUANTIDADE \\
\hline UnB & Ciência Política & Monografia & 18 \\
\hline UnB & Sociologia & Monografia & 4 \\
\hline Faculdade Unida & Ciência das Religiões & Dissertação & 3 \\
\hline UnB & Ciências Sociais & Dissertação & 2 \\
\hline UnB & Gestão de Políticas Públicas & Monografia & 2 \\
\hline Centro Universitário Unieuro & Ciência Política & Dissertação & 1 \\
\hline Faculdade EST & Teologia & Dissertação & 1 \\
\hline PUC-Rio & Ciências Sociais & Dissertação & 1 \\
\hline UCSAL & Direito & Monografia & 1 \\
\hline UEPG & Estudos da Linguagem & Dissertação & 1 \\
\hline UERJ & Sociologia & Tese & 1 \\
\hline UFF & Comunicação & Tese & 1 \\
\hline UFG & Direito & Dissertação & 1 \\
\hline UFMG & Ciência Política & Dissertação & 1 \\
\hline UFOP & Letras & Dissertação & 1 \\
\hline UFPA & Ciência Política & Dissertação & 1 \\
\hline UFPB & Relações Internacionais & Monografia & 1 \\
\hline UFPB & Ciência Política & Dissertação & 1 \\
\hline UFPE & Linguística & Tese & 1 \\
\hline UFPE & Ciência Política & Tese & 1 \\
\hline UFPEL & Ciências Sociais & Dissertação & 1 \\
\hline UFPEL & Ciência Política & Dissertação & 1 \\
\hline UFPR & Planejamento e Governança Pública & Dissertação & 1 \\
\hline UFPR & Políticas Públicas & Tese & 1 \\
\hline UFRGS & Ciência Política & Monografia & 1 \\
\hline UFRJ & Serviço Social & Monografia & 1 \\
\hline UFRRJ & Direito & Monografia & 1 \\
\hline UFSC & Sociologia & Tese & 1 \\
\hline UFU & Direito & Monografia & 1 \\
\hline UnB & Antropologia & Dissertação & 1 \\
\hline
\end{tabular}

${ }^{3}$ Foi constatado que 8 dos 39 artigos publicados são trabalhos derivados de dissertações, monografias e teses dos mesmos autores. 


\begin{tabular}{llcc}
\hline UNIVERSIDADE & DEPARTAMENTO & TIPO & QUANTIDADE \\
\hline UnB & Direitos Humanos e Cidadania & Dissertação & 1 \\
UnB & Economia & Tese & 1 \\
UnB & Serviço Social & Monografia & 1 \\
UnB & Sociologia & Dissertação & 1 \\
Unievangélica & Direito & Monografia & 1 \\
Unipampa & Ciência Política & Monografia & 1 \\
Universidade de Lisboa & Direito & Dissertação & 1 \\
Universidade de Passo Fundo & Direito & Monografia & 1 \\
Universidade Metodista & Ciências da Religião & Dissertação & 1 \\
USP & Ciência Política & Dissertação & 1 \\
USP & Geografia Humana & Dissertação & 1 \\
\hline
\end{tabular}

Elaboração própria. Fonte: Banco de dados da pesquisa.

Como apontado anteriormente, a produção está concentrada nas áreas de ciências humanas, e mais especialmente entre as áreas que compõem as Ciências Sociais - Antropologia, Ciência Política e Sociologia. Com relação a dispersão entre as universidades, nota-se que a Universidade de Brasília encabeça a produção sobre o tema, representando $48 \%$ do total de trabalhos. Isto significa que quase metade das 65 dissertações, monografias e teses desenvolvidas nos últimos dez anos teve sua origem em algum departamento da UnB, com especial ênfase ao de Ciência Política.

Os dados apresentados até agora apresentaram o panorama geral da produção acadêmica sobre o tema, mas falta ainda uma peça fundamental desta revisão. Afinal de contas, sobre o que tratam esses textos? A próxima tabela dará a base para a discussão que se segue.

TABELA 1- Número de trabalhos por "tema"**

\begin{tabular}{lcc}
\hline TEMA & QUANTIDADE & $\%$ \\
\hline Frente Parlamentar Evangélica & 42 & $38 \%$ \\
Bancada Evangélica & 21 & $19 \%$ \\
Bancada Ruralista & 15 & $14 \%$ \\
Frentes Parlamentares & 8 & $7 \%$ \\
Frente Parlamentar da Agropecuária & 6 & $5 \%$ \\
Bancada da Bala & 5 & $5 \%$ \\
Bancada Feminina & 2 & $2 \%$ \\
Bancadas Temáticas & 2 & $2 \%$ \\
Bancada da Bola & 1 & $1 \%$ \\
Bancada da Saúde & 1 & $1 \%$ \\
Bancada Empresarial & 1 & $1 \%$ \\
\hline
\end{tabular}




\begin{tabular}{lcc}
\hline TEMA & QUANTIDADE & $\%$ \\
\hline Bancada Sindical & 1 & $1 \%$ \\
Frente Parlamentar da Segurança Pública & 1 & $1 \%$ \\
Frente Parlamentar do Esporte & 1 & $1 \%$ \\
Frente Parlamentar em Defesa das Comunidades Terapêuticas & 1 & $1 \%$ \\
Frente Parlamentar em Defesa dos Direitos Humanos & 1 & $1 \%$ \\
Frente Parlamentar Mista em Defesa da Indústria Brasileira de Bebidas & 1 & $1 \%$ \\
Frente Parlamentar Mista das Micro e Pequenas Empresas & 1 & $1 \%$ \\
Frente Parlamentar Mista pela igualdade racial e em defesa dos quilombolas & 1 & $1 \%$ \\
Frente Parlamentar pela Valorização do Setor Sucroenergético & 1 & $1 \%$ \\
\hline
\end{tabular}

Elaboração própria. Fonte: Banco de dados da pesquisa.

*Por tratar de duas bancadas específicas ao mesmo tempo, um trabalho foi desmembrado em duas categorias: bancada evangélica e bancada da bala, adicionando um trabalho a cada categoria. Por este motivo, a soma dos trabalhos nesta tabela é igual a 112

No início deste artigo, argumentei que entre as bancadas temáticas e frentes parlamentares são três os casos mais conhecidos: a bancada da bala, a bancada evangélica e a bancada ruralista. Já foi apontado também que a imprecisão conceitual e a maneira de analisar os grupos levam a diferentes denominações do mesmo fenômeno. Por este motivo, optou-se por manter as definições dos próprios autores, e, portanto, na tabela, vemos Bancada Evangélica e Frente Parlamentar Evangélica em linhas separadas. O mesmo vale para a Bancada Ruralista e da Bala e para a Frente Parlamentar da Agropecuária e da Segurança Pública, respectivamente. De todo modo, é possível observar que juntos os termos bancada da bala, bancada evangélica e bancada ruralista somam 41 trabalhos ou $37 \%$ do total da produção dos últimos dez anos. Supondo que se tratam dos mesmos grupos, se adicionarmos também as Frentes Parlamentares da Agropecuária, Evangélica e da Segurança Pública, temos 90 trabalhos, ou $81 \%$ do total dos 111 . Isso significa que há claro predomínio dos textos sobre as bancadas e frentes mais conhecidas e especial ênfase à bancada evangélica e à Frente Parlamentar Evangélica.

TABELA 2 - Número de trabalhos por "enfoque".

\begin{tabular}{lcc}
\hline ENFOQUE DO TRABALHO & QUANTIDADE & $\%$ \\
\hline Estudo de caso (um ou mais grupos) & 72 & $65 \%$ \\
Projeto e/ou questão de interesse & 31 & $28 \%$ \\
Análise geral (de cunho teórico ou metodológico) & 8 & $7 \%$ \\
\hline
\end{tabular}

Elaboração própria. Fonte: Banco de dados da pesquisa.

Como decorrência da preferência por alguns temas nos trabalhos já publicados, há clara concentração da produção em estudos de caso: mais da metade dos textos escritos sobre bancadas temáticas e frentes parlamentares versa sobre apenas um ou mais grupos específicos. Esta é a principal limitação da 
bibliografia já existente, uma vez que apenas oito trabalhos se dedicaram a entender o fenômeno de maneira mais geral. Entre eles, há uma proposta conceitual para compreender as frentes parlamentares (Silva e Araújo, 2019) dois textos sobre a institucionalização destes grupos (Souza, 2017; Cascione, 2018) e um artigo mais recente sobre os obstáculos para a consolidação das frentes como participantes das coalizões presidenciais (Cascione e Araújo, 2020). Tendo em vista que compreender os mecanismos de organização e comportamento dos grupos suprapartidários na política brasileira é de extrema importância não só para os pesquisadores da área, mas também para o público geral interessado no tema, o reduzido número de trabalhos que se dediquem a esta empreitada ainda é um entrave para o maior entendimento das bancadas e frentes.

Como já foi salientado, o corpus da análise desenvolvida neste artigo é composto por trabalhos que abordam o tema da perspectiva do Poder Legislativo nacional, formado pela Câmara dos Deputados e pelo Senado Federal. O registro das frentes é realizado pela Câmara, mas o Ato que formalizou a criação dos grupos admite que senadores também sejam membros, desde que assinem a lista signatária, o que dá origem às frentes conhecidas como Frentes Mistas. Dos 111 textos analisados, 57 buscaram discutir os grupos com base no comportamento dos deputados e senadores membros. Outros 50 tiveram como foco apenas os deputados, frequentemente os atores mais conhecidos pela participação nas frentes parlamentares. Os últimos 4 trabalhos, apesar de anunciarem em seus títulos que o estudo aborda o Congresso Nacional, acabam focando apenas no comportamento dos deputados federais. Nenhum trabalho estudou apenas a atuação dos senadores membros das frentes, nem como estas estariam se organizando separadamente no Senado Federal. Essa lacuna é representativa da própria Ciência Política brasileira, cujos trabaIhos tem privilegiado majoritariamente a Câmara dos Deputados, ao passo que as análises sobre o Senado Federal e o comportamento de seus parlamentares ainda carecem de maior atenção.

De maneira a compreender melhor as escolhas teóricas e metodológicas feitas pelos autores ao trabalharem com o tema das bancadas temáticas e frentes parlamentares, no próximo tópico será apresentada uma breve recuperação dos argumentos dos textos mais citados. Na impossibilidade de abordar no detalhe todos os 111 trabalhos que compõem o corpus deste trabalho, acessar as particularidades dos textos mais difundidos sobre o assunto dá pistas sobre como ele está sendo abordado e reproduzido.

\subsection{Breve análise dos trabalhos mais citados}

O quadro a seguir apresenta os dez textos mais citados em ordem decrescente, de acordo com o número de citações. Além disso, também estão presentes os títulos dos trabalhos, seus autores, ano de publicação e o tipo de produção. 


\begin{tabular}{|c|c|c|c|c|}
\hline POSIÇÃO & TíTULO & AUTOR/ANO & CITAÇÕES & TIPO \\
\hline 1 & $\begin{array}{l}\text { Quem tem medo da bancada evangélica? } \\
\text { Posições sobre moralidade e política no elei- } \\
\text { torado brasileiro, no Congresso Nacional e } \\
\text { na Frente Parlamentar Evangélica }\end{array}$ & $\begin{array}{l}\text { Prandi; } \\
\text { Santos (2017) }\end{array}$ & 74 & Artigo \\
\hline 2 & $\begin{array}{l}\text { A frente parlamentar evangélica: força políti- } \\
\text { ca no estado laico brasileiro }\end{array}$ & Trevisan (2013) & 54 & Artigo \\
\hline 3 & $\begin{array}{l}\text { Doação ou investimento?: a atuação legislati- } \\
\text { va dos parlamentares da bancada ruralista e a } \\
\text { questão do financiamento de campanhas }\end{array}$ & Machado (2014) & 34 & Monografia \\
\hline 4 & $\begin{array}{l}\text { Fim da direita envergonhada? Atuação da } \\
\text { bancada evangélica e da bancada da bala e } \\
\text { os caminhos da representação do conserva- } \\
\text { dorismo no Brasil }\end{array}$ & $\begin{array}{l}\text { Quadros; } \\
\text { Madeira (2018) }\end{array}$ & 33 & Artigo \\
\hline 5 & $\begin{array}{l}\text { A questão agrária no Brasil e a bancada rura- } \\
\text { lista no congresso nacional }\end{array}$ & Costa (2012) & 27 & Dissertação \\
\hline 6 & $\begin{array}{l}\text { A participação da Frente Parlamentar } \\
\text { Evangélica no legislativo brasileiro ação po- } \\
\text { lítica e (in)vocação religiosa }\end{array}$ & Duarte (2012) & 25 & Artigo \\
\hline 7 & $\begin{array}{l}\text { Como os dominantes dominam: o caso da } \\
\text { bancada ruralista }\end{array}$ & $\begin{array}{l}\text { Simionatto; } \\
\text { Costa (2012) }\end{array}$ & 25 & Artigo \\
\hline 8 & $\begin{array}{l}\text { Em Nome de Quem?: a bancada evangélica } \\
\text { e seu projeto de poder }\end{array}$ & Dip (2018) & 25 & Livro \\
\hline 9 & $\begin{array}{l}\text { "A casa dos ímpios se desfará, mas a tenda } \\
\text { dos retos florescerá": a participação da Frente } \\
\text { Parlamentar Evangélica no legislativo brasileiro }\end{array}$ & Duarte (2012) & 22 & Dissertação \\
\hline 10 & $\begin{array}{l}\text { Bancada da Bala: uma onda na maré } \\
\text { conservadora }\end{array}$ & Faganello(2015) & 21 & $\begin{array}{l}\text { Capítulo de } \\
\text { Livro }\end{array}$ \\
\hline
\end{tabular}

Elaboração própria. Fonte: Banco de dados da pesquisa.

Como podemos observar acima, há clara predominância das bancadas evangélica e ruralista quanto aos textos mais citados. A primeira é objeto de seis dos dez trabalhos com mais citações, seguida de três trabalhos sobre os ruralistas e de dois sobre a bancada da bala ${ }^{5}$. Outra questão a ser levantada a partir da análise das citações diz respeito a ausência, entre os dez trabalhos mais citados, de algum dos textos que buscasse discutir a institucionalização das frentes e bancadas e/ou uma proposta metodológica para analisá-las. Esse aspecto reforça o argumento de que ainda não há nenhum arranjo conceitual consolidado para o estudo das bancadas temáticas e frentes parlamentares, o que faz com que cada autor decida a seu modo a definição do grupo, sua composição e sua atuação. Apresentadas as características gerais dos trabalhos mais citados sobre as frentes parlamentares e bancadas temáticas, nos próximos parágrafos avanço brevemente em direção ao seu conteúdo, apresentando possíveis consensos e dissensos dos estudos já

\footnotetext{
${ }^{4}$ As citações foram documentadas, quando disponíveis, de acordo com as plataformas pesquisadas - Google Scholar e WebOfScience - por isso é preciso ter em mente que são estimativas. A pesquisa pelo número citações foi realizada nos dias 26/05/2021 e 27/05/2021.

${ }^{5}$ Como apontado anteriormente, o trabalho de Quadros e Madeira (2018) foi contabilizado duas vezes por abordar duas bancadas específicas.
} 
publicados. Serão desenvolvidos de maneira mais detalhada os argumentos do texto mais citado de cada um dos três grupos mais conhecidos.

Prandi e Santos (2018), autores do artigo mais citado sobre a bancada evangélica, se basearam em duas pesquisas do instituto Datafolha: a primeira, de 2014, com cerca de dez mil eleitores e a segunda, de 2015, com 304 parlamentares. O objetivo foi comparar as opiniões das amostras sobre temas como pobreza, pena de morte, redução da maioridade penal, posse de armas, entre outros, de maneira a observar se haveria algum tipo de correlação entre o que pensam os eleitores evangélicos e os congressistas que se declararam representantes de religiões evangélicas. O principal argumento dos autores é que, ainda que a religião ocupe um importante espaço no que tange às convicções individuais dos eleitores, ela não teria força suficiente para estruturar toda a sociedade. Isto porque, segundo eles, a partir dessas pesquisas foi possível identificar um descolamento entre a opinião dos eleitores e a atuação dos parlamentares, que é dotada de independência e defasagem em relação aos primeiros. Os autores concluem que não haveria, portanto, motivos para temer o crescimento do pentecostalismo no Brasil em relação à democracia, a despeito do engajamento dos evangélicos na esfera política.

O segundo trabalho a ser apresentado é a monografia de Machado (2014). O texto buscou analisar se haveria alguma correspondência entre o financiamento de campanha dos parlamentares da Frente Parlamentar da Agropecuária (FPA) e a sua atuação no Congresso. Para tanto, a autora realizou uma pesquisa junto aos bancos de dados do Tribunal Superior Eleitoral (TSE) acerca das doações recebidas durante as eleições de 2010, associada à análise das proposições de interesse da bancada ruralista. Ela procedeu classificando o ramo de atividade das empresas doadoras e as proposições dos congressistas, e verificou que a FPA contou com sucesso - toda vez que uma decisão favorável ao projeto foi tomada - em mais da metade dos projetos de seu interesse. Entretanto, Machado não consegue comprovar se este sucesso está intimamente relacionado a algum tipo de "pagamento de dívida" aos financiadores de campanha, justamente porque, por mais focalizados que alguns projetos sejam, não é possível identificar que tenham sido propostos para favorecer exatamente uma empresa ou outra.

O artigo de Quadros e Madeira (2018) teve como objetivo analisar, a partir dos discursos e projetos de lei propostos e discutidos entre 2010 e 2017 pelas lideranças da bancada evangélica e da bancada da bala, a perda de força do fenômeno da "direita envergonhada", expressa principalmente por um grupo de deputados ativo e extremamente ideologizado. Segundo Quadros e Madeira, a análise dos discursos evidenciou a tendência de que os deputados evangélicos mobilizassem mais a categoria "conservadorismo", ao passo que os membros da bancada da bala teriam preferência pela categoria "direita". O grupo, formado por cerca de dez deputados - entre eles, o atual presidente Jair Bolsonaro - constitui o que os autores denominaram de "elite não envergonhada" e as bancadas temáticas ocupadas por esses parlamentares seriam apenas a "ponta de lança" de uma direita não envergonhada no geral. Como conclusão, Quadros e Madeira apontam que ainda não é possível prever se o comportamento deixará de ser reativo e restrito a um grupo pequeno de deputados ou se uma expansão será observada a longo prazo. De maneira geral, o que se pode observar a partir de uma breve recuperação dos principais argumentos de alguns dos trabalhos mais citados sobre o tema, é que há um padrão diversificado de tipo de análise, de escolha metodológica 
e de argumentação entre os textos. Essas diferenças serão exploradas no tópico a seguir, que busca discutir os consensos e dissensos da literatura.

\subsection{Balanço da bibliografia}

Do argumento desenvolvido no tópico acima, portanto, depreende-se que no que tange ao conteúdo dos trabalhos desenvolvidos nos últimos dez anos, há um evidente consenso acerca da importância das bancadas temáticas e frentes parlamentares para o andamento dos trabalhos no Legislativo brasileiro, em especial na Câmara dos Deputados. Entretanto, duas fontes principais de divergência chamam a atenção. A primeira delas diz respeito à maneira esses autores enxergam as bancadas e frentes parlamentares: enquanto alguns buscam manter uma posição neutra, apontando seu papel como participantes do processo legislativo tal qual os outros atores presentes no Congresso (Pinheiro, 2010; Coradini, 2010; Silva e Corrêa, 2016; Silva e Araújo, 2019), outros assinalam os pontos negativos das organizações temáticas para a democracia e para grupos específicos como a comunidade LGBTQIA+, por exemplo (Binde, 2010; Dias, 2017; Xavier, 2019; Queiroz, 2019; Vaz, 2019). A segunda fonte de divergência - considerada ainda mais relevante, tendo em vista a importância de poder comparar resultados e reproduzir análises - advém de uma questão já levantada neste artigo: não há um padrão no modo pelo qual as bancadas suprapartidárias são estudadas. A diversificação metodológica pode ser observada com clareza quando se analisa os dez artigos mais citados, uma vez que nenhum deles adotou exatamente o mesmo modo de analisar as bancadas e frentes e o comportamento dos seus membros. Análise de discurso, etnografia, pesquisas de opinião, proposições legislativas específicas, desempenho eleitoral e financiamento de campanha, interações em redes sociais, são apenas alguns exemplos de meios adotados pelos autores para estudar as bancadas e frentes. Entretanto, ainda que haja pelo menos uma proposta de classificação das frentes - a de Araújo (2010) - ela não foi considerada pelos textos mais citados, que vieram todos após a sua publicação.

\section{Considerações finais}

O balanço bibliográfico apresentado neste artigo buscou realizar uma análise dos trabalhos produzidos nos últimos dez anos sobre as bancadas temáticas e frentes parlamentares no Brasil. Na introdução apresentei duas perguntas, que, após a revisão da bibliografia aqui realizada, podem ser parcialmente respondidas. A primeira delas questionava de que maneira o desempenho destes grupos poderia ser observado. Como vimos, há uma diversidade de métodos para observar como se dá o comportamento dos parlamentares, o que leva também, a conclusões diferentes sobre esse comportamento. Há autores que concluem que as bancadas e frentes tem certo predomínio sobre as questões relacionadas aos seus assuntos de interesse, ao passo que outros acreditam não haver motivos para acreditar que realmente há uma atuação organizada desses grupos. Com relação à segunda questão, referente às bases nas quais estaria apoiada a atuação dos parlamentares, foi possível observar que, segundo os autores, o principal meio pelo qual estes fazem valer seus interesses é através de proposições temáticas, e do acompanhamento e/ou reação a elas. Entretanto, os discursos também ocupam uma parcela importante do comportamento dos congressistas tematicamente orientados. 
A partir do levantamento dos textos produzidos e da análise realizada neste artigo, cumpre importante sinalizar algumas questões críticas relacionadas à bibliografia sobre bancadas temáticas e frentes parlamentares no Brasil. As principais lacunas da literatura foram amplamente apontadas ao longo do texto. Entretanto, observação mais detida dos trabalhos mais citados demonstra que foram deixados para trás fatores muito importantes quando se fala em grupos parlamentares suprapartidários. O primeiro deles é a pouca relevância que se dá ao comportamento legislativo propriamente dito. $\bigcirc$ foco, na maioria das vezes, está na análise dos discursos e/ou das proposições de interesses específicos, mas pouco se sabe sobre a participação destes deputados e senadores no que tange às comissões, às votações nominais, às relações com os seus respectivos partidos políticos, etc. É preciso ressaltar também, uma última vez, as várias limitações e consequências que focar nos grupos só conhecidos pode trazer para a literatura em si. Isto porque, jogar luz apenas nas "tríade midiática", além de deixar inexplorada uma série de grupos, também incorre no risco de uma saturação do interesse pelo tema, que pode estar se refletindo, por exemplo, na queda de produções por ano. Ademais, falta nos próprios textos uma avaliação mais crítica dos resultados alcançados por pesquisas anteriores. Como apontado anteriormente, os diagnósticos acerca da participação das bancadas e frentes na política brasileira são os mais diversos. Entretanto, os autores raramente discutem entre si, citando apenas os trabalhos anteriores que suportem seu argumento.

Por fim, algumas sugestões podem ser feitas para a construção de uma agenda futura sobre as bancadas temáticas e frentes parlamentares no Brasil. Essa agenda se desdobra em diversos caminhos possíveis, sendo o primeiro deles a necessidade latente da consolidação de propostas metodológicas e de esquemas de classificação mais abrangentes, que facilitem a reprodução dos trabalhos. Segundo ponto diz respeito à observação do papel que cumpre o Senado Federal no que tange à questão das frentes parlamentares, uma vez que a Câmara dos Deputados tem sido o locus institucional privilegiado das análises. Terceira opção se relaciona à expansão dos estudos para além da atuação específica no Legislativo federal, observando a existência dos grupos nas arenas políticas municipais e estaduais. Resta em aberto também a investigação de como estes grupos se relacionam com o Poder Executivo nos três níveis. Finalmente, a comparação com grupos parlamentares suprapartidários em outros países é fator pouco explorado, e poderia ilustrar os diferentes comportamentos que esse fenômeno desempenha em sistemas políticos pelo mundo.

\section{Referências bibliográficas}

ABRANCHES, Sérgio. (2018), Presidencialismo de coalizão: raízes e evolução do modelo político brasileiro. São Paulo, Companhia das Letras.

ABRANCHES, Sérgio. (1988), "Presidencialismo de coalizão: o dilema institucional brasileiro". Dados, 31, 1: 5-38.

ARAÚJO, Suely Mara Vaz Guimarães de. (2016), Frentes e bancadas parlamentares: uma proposta teórico-metodológica e de agenda de pesquisa. $10^{\circ}$ Encontro da $A B C P$. 
BINDE, João Luis. (2018), Fé demais não cheira bem: análise do perfil e atuação da Frente Parlamentar Evangélica (2003-2014). Dissertação de Mestrado. Universidade Federal de Pernambuco, Recife.

BRUNO, Regina. (2017), "Bancada ruralista, conservadorismo e representação de interesses no Brasil contemporâneo". Questões agrárias, agrícolas e rurais. Conjunturas e políticas públicas, E-papers, Rio de Janeiro, p. 155-168.

CASCIONE, Silvio; ARAÚJO, Suely Mara Vaz Guimarães de. (2019), "Obstáculos para protagonismo das frentes parlamentares em coalizões presidenciais no Brasil". Revista de Sociologia e Política, 27, 72: 1-23.

CASCIONE, Silvio Ricardo Silva (2018). Institucionalização e influência das frentes parlamentares no Congresso brasileiro. Dissertação de Mestrado. Universidade de Brasília, Brasília.

CORADINI, Odaci Luiz. (2008), "Politização de interesses através de frentes parlamentares". Revista TOMO, 13: 75-92.

CORADINI, Odaci Luiz. (2010), "Frentes parlamentares, representação de interesses e alinhamentos políticos". Revista de Sociologia e Política, 18, 36: 241-256.

CORRÊA, Luiz. Carlos. (2015), Veto players e processo decisório: estudo do comportamento da Frente Parlamentar Evangélica na Câmara dos Deputados. Dissertação de Mestrado. Universidade Federal do Pará, Belém.

COSTA, Sandra Helena Gonçalves. (2012), A questão agrária no Brasil e a bancada ruralista no Congresso Nacional. Tese de Doutorado. Universidade de São Paulo, São Paulo.

DIAS, Tainah Biela. (2017), "A frente parlamentar evangélica e os direitos sexuais e reprodutivos: ameaças à laicidade no Brasil contemporâneo". Mandrágora, 23, 2: 179-203.

DIP, Andrea. (2018), Em Nome de Quem?: a bancada evangélica e seu projeto de poder. Rio de Janeiro, Editora José Olympio, 2018.

DUARTE, Tatiane dos Santos. (2011), "A casa dos ímpios se desfará, mas a tenda dos retos florescerá": a participação da Frente Parlamentar Evangélica no legislativo brasileiro. Dissertação de Mestrado. Universidade de Brasília, Brasília.

DUARTE, Tatiane dos Santos. (2012), "A participação da Frente Parlamentar Evangélica no legislativo brasileiro: ação política e (in) vocação religiosa".Ciencias Sociales y Religión/Ciências Sociais e Religião, 14, 17: 53-76.

FAGANELLO, Marco Antonio. (2015), "Bancada da Bala: uma onda na maré conservadora". In: BIANCHI, Alvaro et al. Direita, volver. São Paulo, Editora Fundação Perseu Abramo, p. 145-161.

FIGUEIREDO, Argelina Cheibub; LIMONGI, Fernando de Magalhães Papaterra. (2001), Executivo e Legislativo na nova ordem constitucional. Rio de Janeiro, FGV Editora.

FRADE, Laura. (1996), Bancadas suprapartidárias no Congresso Nacional brasileiro: 1995 - 1996. Dissertação de Mestrado. Universidade de Brasília, Brasília. 
MACHADO, Marcela. (2013), Doação ou investimento?: a atuação legislativa dos parlamentares da bancada ruralista e a questão do financiamento de campanhas. Monografia. Universidade de Brasília, Brasília.

NICOLAU, Jairo. (2017), Representantes de quem?: Os (des) caminhos do seu voto da urna à Câmara dos Deputados. São Paulo, Companhia das Letras.

PIERUCCl, Antônio Flávio. (1989), "Representantes de Deus em Brasília: a bancada evangélica na Constituinte". Ciências Sociais Hoje, 11: 104-132.

PINHEIRO, Marina Brito. (2010), Os dilemas da inclusão de minorias no parlamento brasileiro: a atuação das frentes parlamentares e bancadas temáticas no Congresso Nacional. Dissertação de Mestrado. Universidade Federal de Minas Gerais, Belo Horizonte.

PRANDI, Reginaldo; SANTOS, Renan William dos. (2017), "Quem tem medo da bancada evangélica? Posições sobre moralidade e política no eleitorado brasileiro, no Congresso Nacional e na Frente Parlamentar Evangélica". Tempo Social, 29, 2: 187-214.

QUADROS, Marcos Paulo dos Reis; MADEIRA, Rafael Machado. (2018) "Fim da direita envergonhada? Atuação da bancada evangélica e da bancada da bala e os caminhos da representação do conservadorismo no Brasil". Opinião Pública, 24, 3: 486-522.

QUEIROZ, Larissa Maria de. (2019), "Bancada parlamentar evangélica: uma moral religiosa que limita a aplicação dos direitos humanos". Brazilian Journal of Development, 5, 9: 15317-15330.

RINGE, Nils; VICTOR, Jennifer; CARMAN, Christopher J. (2013),Bridging the information gap: Legislative member organizations as social networks in the United States and the European Union. University of Michigan Press, Michigan.

SILVEIRA, Rafael; ARAÚJO, Suely Mara Vaz Guimarães de. (2019), "Representações políticas alternativas no Congresso Nacional: uma proposta conceitual para compreender as frentes parlamentares." Direito Público, 16, 88.

SIMIONATTO, Ivete; COSTA, Carolina Rodrigues. (2012), "Como os dominantes dominam: o caso da bancada ruralista". Temporalis, 12, 24: 215-237.

SOUSA, Gustavo José Carvalho de. (2017), A institucionalização das frentes parlamentares e a especialização da atividade legislativa na Câmara dos Deputados. Trabalho de Conclusão de Curso. Universidade de Brasília, Brasília.

TREVISAN, Janine. (2013), "A Frente Parlamentar Evangélica: Força política no estado laico brasileiro". Numen, 16, 1.

VAZ, Daniel Victor Moreira Calmon. (2019), O congresso nacional e o estado laico: frente parlamentar evangélica e a (im) possibilidade de ameaça ao estado de direito. Trabalho de Conclusão de Curso. Universidade Católica do Salvador, Salvador.

XAVIER, Glauber Lopes. (2015), "Senhores da Lei, Donos da Terra": o arauto da bancada ruralista na Câmara dos Deputados (2009-2014) ". Estudos Sociedade e Agricultura. 


\section{Resumo}

\section{Revisão da bibliografia sobre bancadas temáticas e frentes parlamentares no Brasil (2011-2021)}

O presente artigo tem como objetivo realizar um balanço bibliográfico da produção sobre bancadas temáticas e frentes parlamentares no Brasil, e para tal empreitada, foram selecionados todos os artigos, capítulos de livro, dissertações, livros e teses publicados entre 2011 e 2021. A investigação dos textos mostrou que os autores concordam sobre a importância dos grupos, mas divergem principalmente sobre as interpretações de sua atuação. De maneira geral, os pontos fortes da literatura analisada são o número de trabalhos produzidos nos últimos anos e as diversas metodologias adotadas por eles. Os pontos fracos dizem respeito à concentração das análises nos casos mais conhecidos, deixando de fora uma gama de outros grupos, e a falta de uma proposta conceitual consolidada sobre o tema.

Palavras-chave: bancadas temáticas; frentes parlamentares; Poder Legislativo; Congresso Nacional; balanço bibliográfico.

\section{Abstract \\ Review of the bibliography on thematic groups and parliamentary fronts in Brazil (2011-2021)}

The present article aims to realize a bibliographic review of the production on thematic caucuses and parliamentary fronts in Brazil, and for such an endeavor, all articles, book chapters, dissertations, books and theses published between 2011 and 2021 were selected. The investigation of the texts showed that the authors agree on the importance of the groups, but mainly diverge on the interpretations of their performance. In general, the strengths of the literature analyzed are the number of papers produced in recent years and the various methodologies adopted by them. The weak points concern the concentration of analysis on the best known cases, leaving out a range of other groups, and the lack of a consolidated conceptual proposal on the subject.

Keywords: thematic groups; parliamentary fronts; legislative power; national congress; bibliographic balance.

\section{Resumen}

\section{Revue de la bibliographie sur les groupes thématiques et les fronts parlementaires au Brésil (2011-2021)}

Cet article vise à réaliser une revue de littérature de la production sur les groupes thématiques et les fronts parlementaires au Brésil. Pour ce faire, tous les articles, chapitres de livres, mémoires, livres et thèses publiés entre 2011 et 2021 ont été retenus. L'examen de ces textes a montré que les auteurs sont d'accord sur l'importance des groupes, mais ils divergent surtout sur les interprétations de leur performance politique. En général, les points forts de la littérature analysée sont: le nombre d'articles produits au cours des dernières années; et la diversité méthodologique adoptée par eux. Cela dit, les points faibles concernent la majorité d'analyses sur les cas les plus connus, en excluant une série d'autres groupes, ainsi que l'absence d'une proposition conceptuelle consolidée sur le thème.

Mots-clés : groupes thématiques ; fronts parlementaires ; pouvoir législatif ; Congrès national; revue de littérature. 